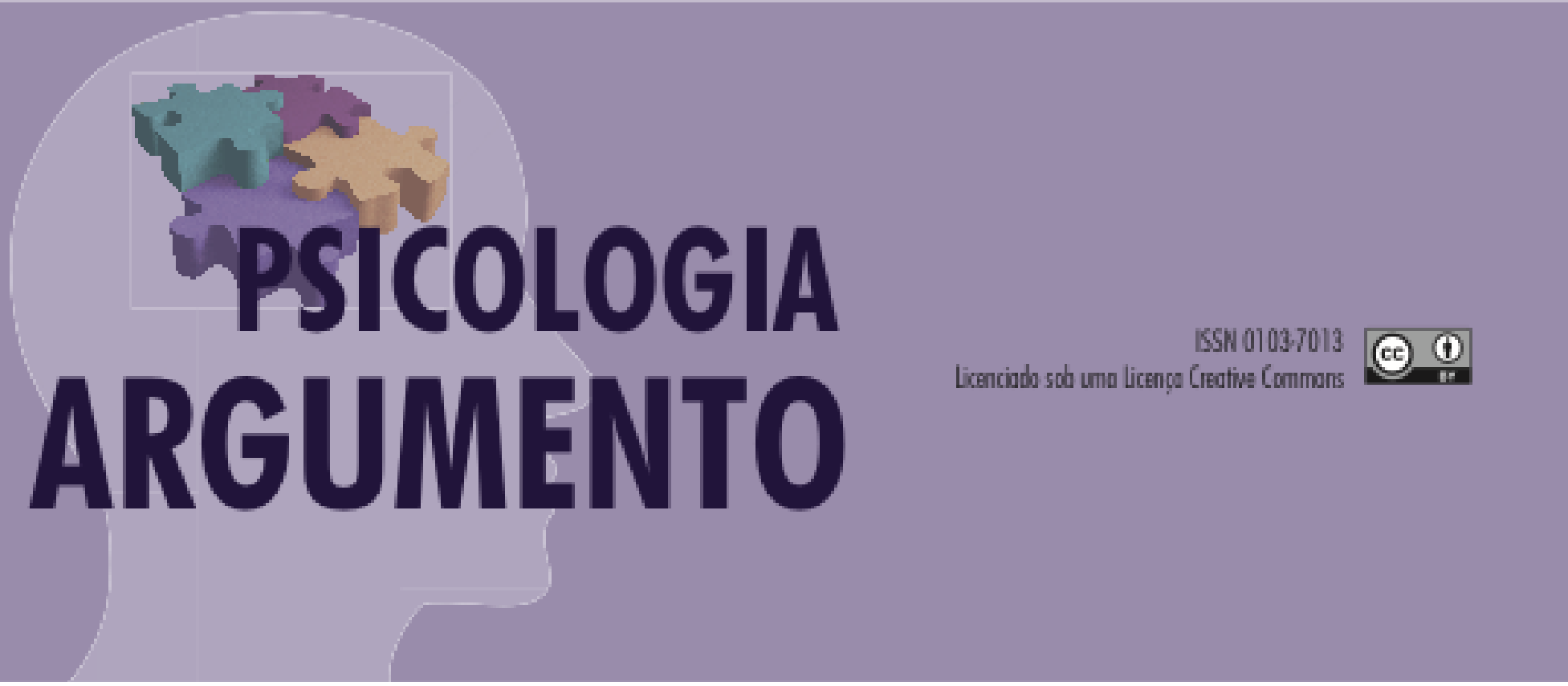

doi: http://dx.doi.org/10.7213/psicolargum.37.97.A002

\title{
Avós que coabitam e compartilham as tarefas parentais
}

Grandmothers that cohabits and share parental tasks

Abuelos que conviven y comparten tareas de los padres

\begin{abstract}
Ana Luíza Xavier Scremin
Mestranda. Programa de Pós Graduação em Psicologia. Universidade Federal de Santa Maria

(UFSM). E-mail: luiza.xavier@gmail.com Orcid: https://orcid.org/0000-0002-4510-1775

\section{Ângela Roos Campeol}

Doutoranda. PPG em Psicologia. Universidade Federal de Santa Catarina (UFSC). E-mail: angela.r.campeol@gmail.com Orcid: https://orcid.org/0000-0003-2010-2285
\end{abstract}

\section{Ana Paula Machado Freitas}

Psicóloga pela Universidade Federal de Santa Maria (UFSM). Email:anapmfreitas@hotmail.com Orcid: https://orcid.org/0000-0001-9526-5703

\section{Karina Scapin Teixeira}

Universidade Federal de Santa Maria(UFSM). E-mail: kaka.s.t@hotmail.com Orcid: https://orcid.org/0000-0002-0751-777X

\section{Caroline Rubin Rossato Pereira}

Professora do curso de psicologia da Universidade Federal de Santa Maria/RS (UFSM). E-mail: carolinerrp@gmail.com.Orcid: https://orcid.org/0000-0001-9861-8391 


\title{
Resumo
}

As famílias, na contemporaneidade, apresentam-sede através de variadas configurações, incluindo as famílias extensas ou transgeracionais. Nestes grupos familiares, os avós com frequência aparecem como importantes figuras de apoio para a organização familiar e para $o$ desempenho das funções parentais. O presente estudo objetivou conhecer a experiência de avós que vivem em famílias intergeracionais. De modo especial, buscou-se compreender a divisão de tarefas parentais entre pais e avós em relação às crianças da família. Participaram do estudo quatro avós que coabitavam com um ou mais netos e ao menos um dos pais das crianças. As participantes responderam a um questionário de dados sociodemográficos a uma entrevista individual. A partir da análise dos dados, identificou-se que as avós referiram participar amplamente dos cuidados dos netos, contudo, houve diferenças entre as famílias em que apenas um dos pais estava presente e aquelas em que ambos faziam parte da família.

Palavras-chave: Avós; Parentalidade; Relações Familiares.

\begin{abstract}
Families nowadays present themselves through various configurations, including extended or transgenerational families. In these family groups, grandparents often appear as important supporting figures for family organization and parenting. This study aimed to know the experience of grandparents living in intergenerational families. Specially, the study sought to understand the division of parental tasks between parents and grandparents in relation to the children of the family. Four grandparents who lived with one or more grandchildren and at least one of the children's parents participated in the study. Participants answered a sociodemographic questionnaire and an individual interview. From the data analysis, it was found that the grandparents reported participating largely in the care of their grandchildren, however, there were differences between families in which only one parent was present and those in which both were part of the family.
\end{abstract}

Keywords: Grandmothers, Parenting, Family Relationships.

\section{Resumen}

Las familias hoy en día se presentan a través de diversas configuraciones, incluidas las familias extendidas o transgeneracionales. En estos grupos familiares, los abuelos a menudo aparecen como figuras de apoyo importantes para la organización familiar y la crianza de los hijos. Este estudio tuvo como objetivo conocer la experiencia de los abuelos que viven en familias intergeneracionales. De manera especial, tratamos de comprender la división de las tareas de los padres entre padres y abuelos en relación con los hijos de la familia. Cuatro abuelos que vivían con uno o más nietos y al menos uno de los padres de los niños participaron en el estudio. Los participantes respondieron un cuestionario de datos sociodemográficos a una entrevista individual. A partir del análisis de datos, se descubrió que los abuelos informaron que participaban en gran medida en el cuidado de sus nietos, sin embargo, habia diferencias entre las familias en las que solo uno de los padres estaba presente y aquellos en los que ambos formaban parte de la familia.

Palabras clave: Abuelos; Crianza de los hijos; Relaciones familiares.

\section{Introdução}

A cada criança que nasce, nascem juntos os avós. Esse acontecimento, traz uma nova posição familiar à essas pessoas, que de pais, passam a ocupar o lugar de avós. Não 
existem regras para cumprir esse papel, podendo acontecer em qualquer idade, morar perto ou longe, conviver ou não (Ramos, 2015). Mesmo que não corresponda à realidade atual, a figura dos avós usualmente ainda é associada a imagens de idosos, que possuem disposição e tempo livre para serem ocupados exclusivamente a serviço de seus netos, para cuidá-los e mimá-los. Segundo Ramos (2015), o lugar social representado pelas avós é relacionado ao papel materno, ocupando o lugar de cuidadora dos netos, envolvidas em tarefas como a educação e socialização dos mesmos. Ainda, imagina-se que gostam de fazer crochê, tricô, passam as tardes fazendo bolo para esperar a chegada dos netos da escola.

Cardoso e Brito (2014) chamam atenção para a diversidade de formas que o ser avó pode ser vivenciado na atualidade. Mesmo que essas avós sejam idosas, existe uma diferença no modo de experienciar a velhice e a função de avó que não condizem com uma visão estereotipada e incluem o envolvimento em atividades prazerosas, que vão além do cuidado com o lar e os netos. De qualquer modo, Osório, Neto e Souza (2018) indicam uma tendênica que direcione seu foco para o grupo familiar, em detrimento dos contatos sociais mais amplos, no momento do nascimento dos netos nas famílias. Ao mesmo tempo em que as avós apontam que gostariam de "aproveitar a vida", a etapa da velhice implica, muitas vezes, em um desinvestimento em relacionamentos fora do núcleo familiar. Assim, conviver com os netos pode ser sentido como uma maneira de renovar alguns interesses. Da parte dos netos, conviver com os avós pode ser benéfico, favorecendo, entre outros aspectos, o conhecimento de sua origem familiar e sua noção de pertencimento a esse grupo (Osório, Neto, \& Souza, 2018).

Ao refletir acerca da experiência de avós que coabitam com os netos, faz-se necessário considerar a pluralidade na apresentação das famílias e a complexidade envolvida em sua organização na atualidade. As famílias desenvolvem-se a partir de trajetórias singulares, que se expressam através de configurações diversificadas e em arranjos habitacionais plurais. Dentre as configurações domiciliares presentes na realidade brasileira, destaca-se a presença das famílias extensas, em que familiares, como as avós, coabitam com seus filhos e netos (Dias, 2015).

O Instituto Brasileiro de Geografia e Estatística (IBGE) utiliza o termo "famílias conviventes" para referir-se às famílias compostas por mais de um núcleo familiar convivendo em uma mesma unidade doméstica. Dados do censo demográfico realizado 
em 2010 mostram que no período entre o ano 2000 e o ano de 2010, a porcentagem de famílias únicas, ou seja, compostas por apenas um núcleo familiar diminuiu 1,5\%, ao mesmo tempo em que a porcentagem de famílias conviventes aumentou 1,5\% (IBGE, 2010). Os dados estatísticos também registram a crescente pluralidade de arranjos familiares, entre os quais destacam-se as famílias recasadas, monoparentais, homoafetivas, intergeracionais e extensas. Deve-se ter em vista que estas configurações familiares totalizam $50,6 \%$ dos lares brasileiros, superando o modelo nuclear, que corresponde a 49,4\% (IBGE, 2010). Nas famílias extensas, a presença significativa dos avós tem como fator relevante o aumento na esperança de vida do ser humano, o que favorece a participação dos avós na vida de seus familiares por um período de tempo maior. Desde a década de 1940 até o momento presente, a expectativa de vida dos brasileiros aumentou mais de 30 anos, sendo atualmente de 75,8 anos (IBGE, 2010).

As relações intergeracionais são os vínculos estabelecidos entre duas ou mais pessoas que pertencem a gerações diferentes possibilitando o compartilhamento de experiências. No que tange às relações estabelecidas nas famílias extensas, Cardoso e Brito (2014) enfatizam a reciprocidade existente na relação avós e netos. Por um lado, os avós desempenham um papel de transmissão intergeracional da identidade e da cultura familiar; por outro, a convivência com os filhos e netos pode responder às necessidades dos próprios avós por atenção e trocas afetivas.

Considera-se, ainda, que a coabitação entre avós, pais e filhos possibilita que os avós compunham, juntamente com os pais das crianças, o subsistema parental na família, compartilhando as tarefas de cuidados e de disciplina. Com isso, aumenta a complexidade do sistema, uma vez que, além dos pais, os avós também precisam ser considerados quanto à divisão de tarefas e decisões em relação à criação dos filhos. Conforme Dias (2015), a maior inter-relação entre as gerações que vivem nesse contexto familiar pode gerar problemas e conflitos frente à necessidade de negociações que extrapolam a dupla parental.

À medida que pais e avós compartilham tarefas parentais e buscam apoiar uns aos outros em suas decisões relativas aos netos, pode-se inferir que se estabelece entre eles uma relação de coparentalidade. Cabe mencionar que a relação coparental surge com a colaboração mútua entre pessoas em função de uma criança ou adolescente, independente do tipo de relação que os cuidadores mantenham entre si (Feinberg \& Kan, 2008). O 
termo coparentalidade foi comumente utilizado para identificar a relação estabelecida entre pais e mães quanto às funções relacionadas a seus filhos, contudo, como indicam os autores, a coparentalidade pode ser estabelecida por diferentes membros da família. Souza, Ramos, Pontes e Silva (2016) apontam que essa expansão do conceito de coparentalidade é compatível com o surgimento das novas configurações familiares, muitas delas estabelecidas com o intuito de garantir o cuidado e o desenvolvimento das crianças e/ou adolescentes.

Ponderando a complexidade das atividades parentais, que envolvem desde os cuidados básicos até a disciplina, pressupõe-se o surgimento de padrões de cooperação e também de conflito entre os adultos que compartilham essas responsabilidades. Além disso, a convivência entre diferentes gerações proporcionada pela coabitação em famílias extensas repercute amplamente na vida dos envolvidos. Em vista disso, o presente estudo objetivou conhecer a experiência de avós que vivem em famílias intergeracionais e compreender a divisão de tarefas parentais entre pais e avós em relação às crianças e adolescentes da família.

\section{Método}

Fizeram parte desta pesquisa quatro avós que coabitavam com um ou mais netos, e ao menos um dos pais das crianças ou adolescentes. As participantes residiam em uma cidade do interior do estado do Rio Grande do Sul e foram acessadas através de indicação e em grupos de atividade física voltados ao público idoso. A idade das mulheres variou de 55 a 79 anos. No momento da realização da pesquisa, todas as mulheres estavam aposentadas e coabitavam com pelo menos um neto. Em uma das quatro famílias apenas o pai da criança residia junto com a avó, configurando-se em uma família monoparental extensa. Nas demais famílias pais e mães das crianças coabitavam com as avós. O tempo médio de coabitação foi de 7,5 anos, variando entre uma semana e 14 anos. No caso em que a família estava morando na mesma residência há uma semana, desde o nascimento do primeiro filho do casal, há quatro anos, as crianças já passavam a maior parte do dia na casa da avó. Na tabela a seguir encontram-se informações das participantes. 


\section{Tabela 1-}

Caracterização dos participantes

\begin{tabular}{lcllc}
\hline Avó & Idade & Estado civil & $\begin{array}{l}\text { Com quem } \\
\text { coabita }\end{array}$ & $\begin{array}{l}\text { Tempo de } \\
\text { coabitação }\end{array}$ \\
\hline 1 & 55 & Casada & $\begin{array}{l}\text { Marido (64), filho } \\
\text { (32) e neta (6) }\end{array}$ & 6 anos \\
2 & 79 & Solteira & $\begin{array}{l}\text { Filha (35), genro } \\
(35) \mathrm{e} \text { dois netos }\end{array}$ & 14 anos \\
& & $\begin{array}{l}(10,14) \\
\text { Filha }(48), \text { genro } \\
(51) \text { e neto (12) }\end{array}$ & 10 anos \\
3 & 71 & Viúva & $\begin{array}{l}\text { Filho (37), nora } \\
(35) \text { e dois netos } \\
(4,4 \text { meses) }\end{array}$ & 1 semana \\
4 & Viúva & &
\end{tabular}

Nota: Em parênteses está a idade em anos das pessoas que coabitam.

Este estudo teve caráter descritivo exploratório, de abordagem qualitativa. A pesquisa qualitativa, de acordo com Minayo (2010), visa acessar o universo de significados, motivos, aspirações, crenças, valores e atitudes dos sujeitos envolvidos no fenômeno investigado.

Após a aprovação do Comitê de Ética, as avós foram convidadas a participar do estudo através de contato telefônico, nos casos de indicações, ou via convite realizado pela própria pesquisadora no grupo de atividade física. Agendou-se, então, um encontro individual com cada uma das participantes que indicaram interesse em participar do estudo. O encontro ocorreu nas dependências da Universidade Federal de Santa Maria. Inicialmente, os procedimentos da pesquisa foram esclarecidos e o Termo de Consentimento Livre e Esclarecido (TCLE) foi lido e assinado pelas participantes. Em seguida, foi solicitado que as avós respondessem a um questionário sociodemográfico e a uma entrevista.

No que tange às diretrizes éticas, a presente pesquisa está baseada na Resolução 510/16 do Conselho Nacional de Saúde que diz respeito às Diretrizes e Normas Regulamentadoras de Pesquisa envolvendo Seres Humanos. Atende, também, a Resolução $n^{\circ}$ 016/2000 do Conselho Federal de Psicologia que destaca os principais critérios que devem ser levados em consideração e seguidos pelo pesquisador durante toda a pesquisa. A pesquisa teve aprovação do comitê de ética da Universidade Federal de Santa Maria, sob o número 69248517.2.0000.5346. 
No que diz respeito aos instrumentos, as avós responderam a um questionário sociodemográfico envolvendo informações como: idade, escolaridade, estado civil e informações sobre a família com quem residiam. A entrevista, por sua vez, abarcou os seguintes tópicos: concepção das participantes sobre ser avó; sua participação nas atividades de cuidado e disciplina dos netos; compartilhamento das tarefas parentais com os pais das crianças ou adolescentes; aspectos positivos e desafios percebidos na coabitação em famílias extensas.

As informações obtidas através das entrevistas foram analisadas de modo conjunto, a partir da técnica de Análise de Conteúdo (Bardin, 1979). Segundo Minayo (2010), a análise qualitativa temática consiste em descobrir os núcleos de sentido que compõem uma comunicação, visando, ainda, atingir um nível de entendimento profundo das falas, que ultrapasse o sentido manifesto do material coletado. Utilizou-se o modelo de estruturação de categorias de tipo aberto, com a criação de categorias a posteriori à aplicação dos instrumentos. Para o processo de análise, após a leitura cautelosa das entrevistas, dois autores do estudo classificaram as falas dos participantes nas categorias de análise. Diante de discordâncias, houve a participação de um terceiro autor e a categorização foi definida por consenso.

\section{Resultados}

Três categorias temáticas foram identificadas a partir da análise dos dados: Relação avós-netos em contexto de coabitação, O papel das avós junto aos netos, Compartilhamento das tarefas parentais entre avós e pais. Os resultados apresentados nas categorias serão exemplificados por vinhetas procedentes das entrevistas. Em seguida, os resultados serão discutidos conjuntamente.

\section{Relação entre avós-netos em contexto de coabitação}

A partir das entrevistas observou-se que, de maneira geral, as avós participantes do estudo relataram possuir uma relação considerada por elas como positiva com os netos, baseada na troca mútua de afeto e conhecimentos com os netos com quem coabitavam. $\mathrm{Na}$ experiência relatada pelas mulheres, ambos, avós e netos, possuíam ganhos decorrente da convivência, como exemplifica a avó 3 "É uma coisa tão gratificante, porque ao 
mesmo tempo que tu ensina o neto, ele te ensina muitas coisas, sabe? É uma troca de experiências, uma troca... Então eu acho muito bom”. "Eu esqueço tudo quando eu tô com as crianças, sabe? Eu não penso em nada. Eu brinco com eles, conto histórias, então aquele tempo que eu tô junto eu acho que é um grande aprimoramento pra vó ou avô que pode ficar junto com os netos". Identificou-se, também, um cuidado e preocupação dos netos em relação às avós, considerando o estágio de vida em que algumas se encontravam: “Ele se preocupa comigo: 'Vó, tu tá bem?'. Porque como eu fiz uma cirurgia há pouco e eu fui infartada também, eu tenho que ter um certo cuidado. E como eu cuido dele, ele também” (A3). Essa troca afetiva entre avós e netos era acompanhada de um compartilhamento de experiências e conhecimento: "Eles têm muito interesse em saber como que era a minha infância. Ai eu conto as histórias e eles ficam com aquele olhinho paradinho, escutando" (A3). Os netos, por sua vez, auxiliavam às avós frente às novidades advindas dos avanços tecnológicos, por exemplo: "Vó porque tu não compra um computador pra ti? Compra porque dai eu te ensino” (A2); "Eu aprendi muito com os meus netos, muita coisa. Eu não sabia mexer no celular, eles me ensinaram, no notebook, eles me ensinam tudo" (A3).

Diante da fase do ciclo de vida em que as avós encontravam-se, marcada por perdas sociais e pessoais, como do cônjuge, conviver com os netos era experienciado como uma forma de renovar o interesse na vida e de estabelecer relacionamentos de proximidade, como relatou A4: A gente passou por uma fase muito dificil com a perda do meu marido, ele morreu meio de repente, entende? Então a minha vida deu uma guinada e eu me agarrei muito no P. (neto)". Além disso, a convivência com os netos crianças ou adolescentes e os aspectos da infância repercutiram positivamente na vida das avós: "Eu brinco com eles, conto histórias. Então, aquele tempo que eu tô junto eu acho que é um grande aprimoramento pra avó ou avô que pode ficar junto com os netos" (A3). Uma das participantes declarou: "Eu prefiro isso aí, a bagunça, os gritos, a correria dentro de casa. Isso faz bem. Foi muito importante eles na minha vida” (A4). Em geral, as avós demonstraram satisfação em relação às suas vivências com os netos com os quais coabitavam: "Eu amo ser avó. Sou avó bem coruja" "Acho que é o maior presente que eu ganhei porque tu te completa" (A3).

Por outro lado, considerando-se as dificuldades de ser avós residindo com os netos, uma das participantes relatou sentir-se sobrecarregada com as atividades parentais 
realizadas diariamente: "Mas é que, assim, tu cuida de manhã, de tarde, de noite. Tu faz tudo pela criança. Na idade que eu tô, eu não sou mais uma jovem, não estaria mais no tempo de eu criar filho, então, eu me canso"(A2).

\section{Tarefas desempenhadas pelas avós junto aos netos: o papel das avós}

As entrevistas analisadas evidenciaram diferenças a respeito das tarefas assumidas pelas avós, conforme as configurações familiares nas quais estavam inseridas, sendo apenas A1 parte de uma família monoparental extensa, enquanto que as demais avós coabitavam com seus netos e ambos os pais desses. Nas famílias extensas em que coabitavam ambos os pais, crianças e avós, o principal envolvimento das avós na rotina familiar apresentou-se como atividades de auxílio, quando os pais estavam trabalhando, como, por exemplo: "Eu sou mais quando eles não estão” (A2); "Quando a minha nora chega ela assume, e meu filho também. Eles assumem tudo. Só quando eles não estão que eu fico cuidando deles" (A4).

Além de fazer companhia aos netos quando os pais não estavam presentes, as avós envolviam-se com tarefas de cuidado no dia-a-dia dos netos: "Eu faço tudo por eles, a sopinha, ajudo a trocar fralda, só as roupas que eu não lavo, (...) o resto tudo eu faço. Passeio com eles" (A4); "Ela (mãe da criança) dava banho, eu trocava a roupa, levava pra escola, ajudava sempre nas tarefas. Sempre eu participei bastante com ele em casa" (A3). As avós realizavam funções de cuidado visando o apoio e a cooperação dentro da família.

Sobre a responsabilidade a respeito da educação dos netos, as participantes provenientes das famílias em que ambos os pais estavam presentes afirmaram não assumir o papel de educadoras. Quando questionadas sobre a educação dos netos, a participante A3 afirmou não possuir essa responsabilidade: "Não, eu acho que a educação cabe aos pais. Eu acho que avó é mais pra ajudar, pra brincar, ensinar coisas".

$\mathrm{Na}$ família da participante A1, que se configurava como uma família monoparental masculina extensa (apenas o pai da criança estava presente), o papel assumido pela avó, além dos cuidados diários, incluiu tarefas educativas. A avó relatou realizar atividades cotidianas de cuidado da neta, como alimentação, dar banho, levar para a escola: "Eu levo ela sempre pra escola e ele (pai) busca quando ele pode" (A1). Além disso, a avó A1 declarou, ainda, ser a responsável pela educação de sua neta e assumir 
tarefas consideradas por ela como maternas: "É mostrar o certo. Alguém tem que mostrar o certo, pelo menos até a criança entender um pouco. (...) E como nesse caso eu que tô no lugar da mãe, eu penso que eu tenho a obrigação de ensinar as coisas que eu acho certo". Por outro lado, diferenciava sua postura em relação ao papel de mãe, assumindo mais o papel da avó que mima a neta: "Hoje, graças a deus, bem madura, eu tenho o meu salário, (...) a gente consegue comprar presentinhos, comprar roupinha bonita, comprar guloseimas e, enfim, ajudo ela como se fosse minha filha. Mas eu noto que sim, é 'mãe com açúcar', porque a gente é mãe duas vezes e mãe com açúcar, a vó” (A1).

Apesar de assumirem papéis parentais, as avós também apontaram diferenças no modo como participavam dos cuidados e da educação dos netos em relação a forma como haviam criado seus próprios filhos quando esses eram crianças: "Existe uma grande diferença, né? Com os netos a gente consegue ser mais paciente, porque a gente vai adquirindo muita experiência com o passar do tempo" (A4); "No tempo dos meus (filhos), ou por falta de maturidade, ou por falta de entendimento, sei lá, eu apelava para o chinelo. (...) Já com a neta, não. Eu acho que a gente tá mais descansada” (A1).

\section{Compartilhamento das tarefas parentais entre pais e avós}

Quanto ao compartilhamento das tarefas de educação e cuidado das crianças por pais e avós, percebeu-se, também, uma diferença na forma como eram realizadas as combinações nos diferentes contextos familiares. Nas famílias intergeracionais em que estavam presentes avós e ambos os pais, a função referente à educação das crianças era consensualmente considerada de responsabilidade principal dos pais, sendo necessário o diálogo entre os adultos envolvidos (pai, mãe e avó) a fim de apoiarem-se na educação das crianças ou adolescentes: "A gente sempre combina. (...). A gente procura, como adultos, conversar sem a criança estar presente. Agora, a decisão é deles. Quanto às tarefas, os horários, é tudo eles que elaboram, mas eu converso quando eu vejo que alguma coisa não está bem”; "A gente conversa muito. (...) Eles educam e eu não deseduco, eu complemento" (A4).

Contudo, as avós ressaltaram que participavam dando suas opiniões quando julgavam necessário: "Meu filho é meio contra, não é pra mim me meter. Mas tem certas coisas que eu falo" (A2); "Em casa a gente tem essa tendência de querer interferir, de vez em quando..., aí dá os atritos. Eu procuro não interferir, mas de vez em quando tu 
tem que, não tem como tu não interferir, sabe?" (A3). Algumas vezes essa interferência das avós não era bem recebida pelos pais das crianças, como ressaltou A3: “Às vezes, eles (pais) não aceitam, sabe? A gente que tem mais vivência e quer passar pra eles. E eles não aceitam isso".

Ainda que as avós contribuíssem com suas opiniões, pareceu haver cautela quanto às interferências nas decisões dos pais, visando evitar conflitos na educação das crianças: "Eu acho que cabe aos pais a educação, porque se não a criança não sabe se respeita a mãe, o pai ou a avó" (A3); "os pais educam e a gente intensifica né? Mas com carinho!" (A4). Diferentemente das demais famílias, no caso da família monoparental extensa, identificou-se que pai e avó concordavam que ela (avó) tinha autonomia para decidir sobre sua conduta em relação à educação da neta, já que esta era quem realizava a maioria dos cuidados e passava o maior período do dia com a criança: "O meu filho, ele sabe da mãe que tem. (...) Então ele diz: 'Mãe, tu que cria ela enquanto eu não tô. Faz como tu acha que tem que fazer'. Então, não interfere muito na criação, porque trabalha fora" (A1). Contudo, isso não excluía a necessidade de negociação entre o pai e a avó sobre o cuidado da criança, sendo importante estabelecer condutas comuns a todos os responsáveis. Nesse caso em específico, em alguns momentos, o pai dividia com a avó sua opinião a respeito da maneira como ela conduzia os cuidados e a educação da criança: "Não que ele se meta, a gente se acerta, porque ele sabe que eu tento fazer o melhor pra ela. (...) Às vezes ele diz: 'Mãe, procura não dar as coisas pra ela quando ela desobedece. Mãe, eu acho que tu tem que dar castigo"," (A1).

\section{Discussão}

As avós do estudo demonstraram possuir uma relação amorosa, baseada no carinho e cuidado com os netos com quem coabitavam. As participantes relataram despender de tempo para participar do cotidiano dos netos, enquanto estes renovavam o sentido da vida para elas, preenchendo, muitas vezes, um vazio produzido pelas perdas advindas com a fase do ciclo vital em que se encontravam. Os idosos, de acordo com Carter e McGoldrick (1995), possuem menos relacionamentos que possam ajudar a superar as mudanças típicas desse período do desenvolvimento, quando a perda de amigos e parentes torna-se algo mais comum e recorrente. Especialmente, a perda do cônjuge 
pode acarretar dificuldades na (re)organização para uma vida sozinha, devido ao longo tempo de vida conjugal.

Diante de um contexto de aposentadoria, doenças e perda de cônjuge, o convívio com os netos concede um sentimento de utilidade para os avós, de modo que os netos podem reavivar desejos, sonhos e ideais esquecidos (Kipper e Lopes, 2006). Além disso, o convívio com as crianças também é capaz de proporcionar a troca de experiências e conhecimentos entre as gerações, afinal, enquanto as avós passavam seus ensinamentos, aprendiam com as brincadeiras e alegrias da infância. Nessa direção, a pesquisa realizada por Cardoso e Brito (2014), apontou para o interesse das avós para cuidar dos netos, como forma de preencher o vazio que sentiam, devido ao sentimento de solidão. A participação ativa na vida dos netos, também foi evidenciada no estudo de Araújo e Dias (2010), em que participaram dez avós que cuidavam dos netos. Essas avós demonstraram sentimento de satisfação e felicidade por estarem na companhia das crianças, tornando-se o objetivo de vida. Ademais, a sobrecarga com as atividades relacionadas aos netos também se faz presente. Por vezes, as responsabilidades com as tarefas do dia a dia das crianças, acabavam prejudicando o tempo que as avós tinham para dedicar-se às suas atividades pessoais. Tal resultado está de acordo com os achados de Cardoso e Brito (2014), em que as avós indicam a falta de tempo para realizar suas atividades pessoais devido ao tempo demandado com o cuidado dos netos. Nesse sentido, o estudo de caso realizado por Pinto, Arrais e Brasil (2014) com uma avó que desempenhava o papel de apoio parental de uma adolescente de 15 anos, demonstrou que a avó exercia a função de "mãe substituta", vivenciando por isso, uma sobrecarga emocional e física. A este respeito, Vitale (2008) defende que o processo de tornar-se avó ou avô que compartilha as atividades parentais dos netos não é composto apenas por experiências prazerosas. Além disso, como ressalta Molinier (2004), é de esperar-se que ocorram flutuações de sentimento quando se estabelece uma relação intensa de cuidado com o outro.

Entre as avós participantes do estudo, independentemente da configuração familiar da qual essas faziam parte, destaca-se a importância atribuída ao apoio das avós para o dia a dia das famílias, a organização da rotina de vida familiar e, de modo especial, o cuidado dos netos. Dias, Hora e Aguiar (2010) observam que avôs e avós tornam-se importantes fontes de apoio nos contextos em que os pais têm cada vez menos tempo para dedicarem-se aos filhos. Na busca de melhores condições para suas famílias, homens e 
mulheres dedicam boa parte de seu tempo a suas atividades profissionais, tornando necessário que outras pessoas auxiliem no cuidado com os filhos. Somado a isso, a condição de aposentados e a estabilidade financeira das avós pode torná-las mais disponíveis para o cuidado dos netos do que propriamente os pais (Cardoso e Brito 2014). A este respeito, algumas das avós do estudo de Cardoso e Brito (2014) relataram partir delas a ideia de cuidar dos netos, em vista à dificuldade dos pais em assumirem suas atividades profissionais paralelamente ao cuidado com os filhos. Além disso, Lopes, Neri e Park (2005) salientam que na ausência dos pais, a participação das avós na criação das crianças e adolescentes pode ser benéfica para os netos, pois eles poderão ter uma sensação de pertencimento à sua família de origem.

Com relação ao compartilhamento de tarefas parentais entre as avós e os pais, em especial no tocante à educação das crianças, identificou-se peculiaridades conforme os arranjos familiares das avós. Nas configurações em que ambos os pais estavam presentes, apesar de não se observar um acordo explícito e, embora as avós opinassem quando necessário, a decisão final era sempre dos pais. Nesse contexto, as avós sentiam-se mais confortáveis para compartilhar momentos com os netos com menos cobranças, já que não precisavam assumir uma função parental. Em vista disso, entende-se que nestas famílias o papel parental de educação e disciplina era designado prioritariamente aos pais das crianças ou adolescentes, enquanto que as avós compartilhavam com esses os cuidados diários dos netos.

Dias, et al. (2010), em sua pesquisa com netos e netas que coabitavam com os pais e avós, sinalizaram que algumas avós foram consideradas como "coeducadoras" dos netos, uma vez que, apesar de não assumirem sozinhas as responsabilidades a respeito da educação das crianças, compartilhavam as tarefas com os pais, estes vistos como os principais responsáveis pelo cuidado. No presente estudo, no caso das participantes que coabitavam com ambos os pais e os netos, embora a educação da prole não parecesse ser algo compartilhado entre pais e avós, estas contribuíam com a educação dos netos quando julgavam necessário, centrando-se nas questões mais cotidianas.

Billé (2002), autor francês, ressalta que aos avós é atribuído um papel muito sutil, pois devem estar aptos para cuidar dos netos sem, no entanto, assumir o papel de pais. São convocados a dar conselhos, porém sem julgar, mostrar caminhos possíveis sem envolverem-se na educação proposta pelos pais. Este limite parece mais difícil de ser 
mantido quando pais e avós residem na mesma casa e compartilham tarefas cotidianas de cuidado e educação das crianças. Considera-se importante que, nestes casos, haja a delimitação conjunta de posturas e regras a serem mantidas por todos junto às crianças. Quando as responsabilidades divididas entre pais e avós não estão claras, o cuidado dos netos pode acarretar conflitos com os pais em função das diferentes concepções sobre a criação dos netos, reverberando na vida das avós (Lopes et al., 2005). Nessa perspectiva, Zanatta e Arpini (2017), a partir de uma pesquisa que propôs investigar as "novas" configurações da imagem, do papel e da função das avós, encontraram que a responsabilização dos pais das crianças pela educação dos filhos, eximiu as avós do papel materno, podendo usufruir com os netos de momentos leves, marcados pela alegria e satisfação. Em contra partida, percebeu-se na família monoparental extensa um envolvimento mais intenso da avó na criação da neta, sendo realizados ajustamentos nas atribuições comumente designadas aos papéis de pais e de avós. Neste arranjo familiar, a avó tinha mais autonomia para tomar decisões referentes à neta, ainda que pai e avó conversassem sobre os cuidados. Na ausência da figura materna, o lugar ocupado pela avó nesta família remete à uma reflexão sobre a concepção acerca do papel atribuído a homens e a mulheres no cuidado das crianças em nossa sociedade. Conforme RochaCoutinho (2005), ainda está presente na sociedade a noção de que as mulheres estariam mais preparadas para o cuidado com a casa e com os filhos, sendo estas atribuições majoritariamente ligadas ao feminino (Rocha-Coutinho, 2005).

Ao considerar a sua tarefa como vinculada ao papel da mãe na família, ao assumirem a responsabilidade e o cuidado integral dos netos, as avós do estudo de Cardoso e Brito (2014) consideravam desempenhar o papel de "mães substitutas" dos netos. Pesquisas realizadas por Oliveira, Vianna e Cárdenas (2010) e Mainetti e Wanderbroocke (2013) com avós encarregadas de criar os netos indicaram que elas também percebiam o papel desempenhado por elas como similar ao de mãe. Neste sentido, de acordo com Rabinovich, Moreira e Franco (2012), a criação das crianças é influenciada por outras mulheres do convívio familiar, além da própria mãe das crianças, em destaque as avós.

Cabe ressaltar que desde o século XVIII, juntamente com o surgimento do sentimento de família e de infância, o papel das mulheres esteve fortemente associado ao cuidado das crianças e da casa, enquanto que os homens assumiriam as necessidades 
financeiras da família e os espaços públicos. Ainda que, como resultado de movimentos importantes vivenciados na segunda metade do século XX, o cenário atual seja composto por uma crescente participação das mulheres no mercado de trabalho e no sustento econômico do lar, os afazeres domésticos e o cuidado com os filhos continuam estereotipadamente atrelados a características tidas como femininas. Com isso, as transformações na vida profissional da mulher não parecem estar sendo acompanhadas na mesma proporção por uma divisão mais igualitária das tarefas domésticas, criação e educação dos filhos entre homens e mulheres (Wagner, Predebon, Mosmann \& Verza, 2005).

Bueno, bossardi e Vieira (2015) evidenciam que, a forma como a família tem se organizado para dar conta das tarefas do dia a dia, vão além de um modelo prédeterminado. Atualmente, a família busca uma maior igualdade na divisão de tarefas, não sendo desempenhadas por somente um dos pais. No caso da família monoparental masculina extensa, referida neste estudo, percebeu-se que as tarefas parentais foram assumidas por outro membro familiar que não um dos pais biológicos da criança, apontando para a multiplicidade das organizações familiares e distribuição de papéis presentes nas famílias contemporâneas. Em um primeiro momento, pode-se pressupor a necessidade de rever esses papéis para que as funções de pai e mãe retornem a eles e não recaiam sobre outros membros da família. Todavia, Attias-Donfut e Segalen (2001) salientam que o envolvimento no cuidado dos netos deve constituir-se em uma relação voluntária, a ser negociada entre os envolvidos. Pensando na criação das crianças ou adolescentes, Ceccarelli (2007) argumenta que não há um único arranjo familiar que garanta um desenvolvimento sadio para a constituição do indivíduo, prevalecendo a preocupação com a qualidade do cuidado desempenhado e da relação estabelecida.

\section{Considerações finais}

Ao longo da história, as avós estiveram fortemente associadas a figuras de apoio para pais de primeira viagem ou mesmo para os pais mais experientes. Apesar das maiores distâncias geográficas entre os membros das famílias e da permanência das avós por mais tempo no mercado de trabalho, as novas configurações familiares, o envolvimento das mulheres no universo do trabalho e o aumento da longevidade podem ser pensados como 
fatores que colaboram para aproximar as avós de seus descendentes na atualidade. Assim, uma pluralidade de fenômenos sociais tem contribuído para o aumento no número de lares compostos por diferentes gerações, entre eles, os domicílios em que avós, pais e netos coabitam.

O papel da avó na família contemporânea parece acompanhar as mudanças sociais, visto que não se apresenta como uma função estática e limitada. No que diz respeito às tarefas parentais desempenhadas pelas avós, em um contexto de família extensa, observou-se que a configuração familiar pode influenciar no papel ocupado pela avó dentro do sistema. Em todos os casos, contudo, pais e avós, em contexto de coabitação, precisam estabelecer uma relação de coparentalidade à medida que compartilham as tarefas parentais relacionadas às crianças.

Gradualmente, a família nuclear tradicional vem cedendo lugar a outras organizações, indicando que o sistema familiar não é uma unidade imutável. Em vista das transformações que a família contemporânea vem atravessando, destaca-se a relevância de aprofundar o conhecimento a respeito das novas configurações familiares, dentre elas as famílias extensas ou chamadas famílias intergeracionais que coabitam, visando compreender quais os caminhos encontrados pelas famílias para cumprir seu papel social e os impactos desta organização familiar na vida de seus integrantes.

Reconhece-se a existência de limitações no presente estudo, em vista de constituir-se como um estudo exploratório de aproximação da experiência das famílias extensas a partir da perspectiva unilateral das avós. Outros fatores relevantes para a criação das crianças e adolescentes nas famílias e características das relações intergeracionais não foram aprofundados neste estudo. Considera-se relevante, também, investigar a coabitação das avós em outros arranjos familiares como, por exemplo, as famílias recasadas e monoparentais femininas. Além disso, as transformações contemporâneas contribuem para uma maior participação dos avôs nas tarefas parentais dos netos, reforçando a necessidade de mais pesquisas sobre o tema. 


\section{Referências}

Araújo, C. P., \& Dias, C. M. de S. B. (2010). Avós guardiões de baixa renda. Pesquisas e Práticas Psicossociais. 4(2), 229-237. Recuperado de: https://www.ufsj.edu.br/portal2repositorio/File/revistalapip/volume4_n2/araujo_e_dias.pdf

Attias-Donfut, C., \& Segalen, M. (2001). Le invention de la grand-parentalité. In: D. Gall \& Y. Bettahar (Orgs.). La pluriparentalité. (pp. 243-260), Paris: Universitaires de France.

Bardin, L. (1979). Análise de conteúdo. Lisboa: Edições 70.

Billé, M. (2002). A quoi servent les grands-parents? Des grands-parents pour intro-duire au "sacré". Dialogue - Recherches cliniques et sociologiques sur le couple et la famille, $4^{\circ}$ trim., 3-10.

Bueno, R. V.Bossardi, C. N., \& Vieira, M. L. (2015). Papel do pai no contexto contemporâneo. In: E. R. Goetz \& M.L. Vieira (orgs) Novo Pai. (pp.109-124). Paraná: Juruá.

Carter, B., McGoldrick, M.; cols. (1995). As Mudanças no Ciclo de Vida Familiar: Uma Estrutura para a Terapia Familiar. Artmed; Edição: 2.

Cardoso, A. R., \& Brito, L. M. T. (2014). Ser avó na família contemporânea: que jeito é esse? Psico-USF, 19(3), 433-441. Recuperado de: http://www.scielo.br/ pdf/ pusf/ v19n3/07.pdf

Ceccarelli, P. R. (2007). Novas configurações familiares: mitos e verdades. Jornal de Psicanálise, 40(72), 89-102. Recuperado de: http://pepsic.bvsalud.org/ pdf/jp/ v40n72/ v40n72a07.pdf

Conselho Federal de Psicologia. Resolução 016/2000. Recuperado em 01 de maio de 2017, de http://site.cfp.org.br/wp-content/uploads/2000/12/resolucao2000_16.pdf.

Conselho Nacional de Saúde. Resolução do Conselho Nacional de Saúde 466/12.Recuperado em 01 de maio de 2017, de http://conselho.saude.gov.br/resolucoes/2012/Reso466.pdf.

Coutrim, R. M.E. Figueiredo ,A. M., Oliveira, J.A., \&amp; Resende, A. (2018). O papel dos avós nos cuidados com a educação e a saúde das crianças. Revista de Estudos Aplicados em Educação, v. 3( 5),101-110 .

Dias, M. B. (2015). Manual de Direito das Famílias. 10ª Edição. Revista dos Tribunais.

Dias, C. M. S. B., Hora, F. F. A., \& Aguiar, A. G. S. (2010). Jovens criados por avôs e por um ou ambos os pais. Psicologia: Teoria e Prática, 12(2), 188-199. Recuperado de: http://pepsic.bvsalud.org/pdf/ptp/v12n2/v12n2a13.pdf 
Feinberg, M. E., \& Kan, M. L. (2008). Establishing family foundations: intervention effects on coparenting, parent/infant well-being, and parent-child relations. Journal of Family Psychology, 22(2), 253-263.

Instituto Brasileiro de Geografia e Estatística (2010). Família e Domicílio. Recuperado em 01 de maio de 2017, de http://censo2010.ibge.gov.br/.

Kipper, C. D. R., \& Lopes, R. S. (2006). O tornar-se avó no processo de individuação. Psicologia: Teoria e Pesquisa, 22(1), 29-34. Recuperado de: http://www.scielo.br/pdf/ptp/v22n1/29841.pdf

Lopes, E. D. L., Neri, A. L., \& Park, M. B. (2005). Ser avós ou ser pais: os papéis dos avós na sociedade contemporânea. Textos sobre Envelhecimento, 8(2), 239-253. Recuperado de: http://www.scielo.br/pdf/pusf/v19n3/07.pdf

Mainetti, A. C., \& Wanderbroocke, A. C. N. D. S. (2013). Avós que assumem a criação de netos. Pensando Famílias, 17(1), 87-98. Recuperado de: http://pepsic.bvsalud.org/ pdf/ penf/v17n1/v17n1a09.pdf

Minayo, M. C. S. (2010). O desafio do conhecimento: pesquisa qualitativa em saúde. Ed. 12. São Paulo: Hucitec.

Molinier, P. (2004). O ódio e o amor, caixa preta do feminismo? Uma crítica da ética do devotamento. Psicologia em Revista, 16, 227-42. Recuperado de: https://pdfs.semanticscholar.org/5be6/fda1b7be8ded2a7363e88e1ab21e6ac1f229.pdf ? ga=2.37262496.1651677004.1569598774-642664567.1569598774

Oliveira, A. R. V., Vianna, L. G. \& Cárdenas, C. J. (2010). Avosidade: visões de avós e de seus netos no período da infância. Revista Brasileira de Geriatria e Gerontologia, 13(3), 461- 474. Recuperado de: http://www.scielo.br/pdf/rbgg/v13n3/a12v13n3.pdf

Osório N. B., Neto, L. S., \& Souza, J. M. (2018). A era dos avós contemporâneos na educação dos netos e relações familiares: um estudo de caso na universidade da maturidade da universidade federal do Tocantins. Revista Signos, 39(1), 305-315. Recuperado de: http://www.univates.br/revistas/index.php/signos/article/view/1837/1358

Pinto, K. L. B., Arrais, A. R., \& Brasil, K. C. T. R. (2014). Avosidade X maternidade: Avó como suporte parental na adolescência. Psico-USF, 19(1), 37-47. Recuperado de: http://www.scielo.br/pdf/pusf/v19n1/a05v19n1.pdf

Rabinovich, E. P., \& Moreira, L. V. C. (2008). Significados de família para crianças paulistas. Psicologia em Estudo, 13(3), 447-455. Recuperado de: http://www.scielo.br/pdf/pe/v13n3/v13n3a05.pdf 
Rocha-Coutinho, M. L. (2005). O papel de homens e mulheres na família: podemos falar em reestruturação? Psicologia Clínica, 15(2), 93-108.

Ramos, A. C. (2015). Os Avós na Literatura Infantil: perspectivas gerontológicas e educacionais. Educação \& Realidade, 40(1), 191-225. Recuperado de: http://www.scielo.br/pdf/edreal/v40n1/2175-6236-edreal-40-01-00191.pdf

Souza, P. B. M. D., Ramos, M. D. S., Pontes, F. A. R., \& Silva, S. S. D. C. (2016). Coparentalidade: um estudo de revisão sistemática de literatura. Estilos da Clínica, 21(3),700-720. Recuperado de: http://pepsic.bvsalud.org/ pdf/estic/ v21n3/ a09 v21n3.pdf

Vitale, M. A. F. (2008). Avós: velhas e novas figuras da família contemporânea. Família: redes, laços e políticas públicas, 5, 93-105.

Zanatta, E., \& Arpini, D. M. (2017). Conhecendo a imagem, o papel e a relação avó-neto: a perspectiva de avós maternas. Estudos e Pesquisas em Psicologia, 17(1), 343-363. Recuperado de: https://www.e-publicacoes.uerj.br/ index.php/revispsi/ article/ view/ $\underline{35164 / 24865}$ 